\title{
Emplacing the Other, or How Dignity Plays
}

Abstract: In times challenging the very standing of otherness, the urgent call of serious work to be done, especially on behalf of others in need of essential dignity, would seem to avoid any diversion onto the fields of play. Yet such a non-sequitur might be contested by the notable history of enquiry into the critical agency of play, from Plato through Schiller to Marcuse, or by how certain playing fields, from actual Olympic venues to the fictional courts of Foster Wallace's Eschaton, shed light on place-making strategies in general, and their resulting inscriptions of territorial dignities/indignities. According to Jane V. Curran and Christophe Fricker, Schiller's treatise On Grace and Dignity suggests that grace (athletic or otherwise) typically originates the sensual, elevating movement in time, to be subsequently "corrected" by the weight of moral dignity, coalescing in form. But could an alternative sequence grant dignity as the initial impulse, as the uplift for the prerequisite posture necessary to undergird grace that artfully skitters relative to gravity? In Schiller's Aesthetic Letters, the union, or perhaps intersection, between grace and dignity, is suggested as the province of play, much like the term "place" might be seen as a strong middle condition between the polarities of space and time. This article, more like a series of tentative mappings, tries to examine roles of place and play relative to matters of dignity from the vantage-point of an architect straddling practice and teaching, in an uneasy relation between the spatial arts and the literary arts.

Keywords: dignity, place, otherness

The seeming keyboard slipup muddling the title of our ICLA Vienna 2016 panel session (from "Embracing the Other" to "Emplacing the Other") was intended as a provocation to those gathered at the ICLA conference across contrasting disciplines, from the spatial arts to the literary arts. As an architect straddling teaching and practice, I have become accustomed to uneasy relationships across territorial boundaries, which often break down into their presumed space-time oppositions. In educating architectural students, the initiation into architecture's very definition was historically proselytized in Bruno Zevi's classic book title, Architecture as Space. In the cause of progressive modernism, however, a reductive implication of the text drew an oppositional line across the space-time continuum, a separation between the timeless stasis of painting and architecture and the timeful kinetics of theatre, literature, and music. But we should also note F. W. J. Schelling's

2 Open Access. (C) 2021 Stuart Romm, published by De Gruyter. (c) BY-NC-ND This work is licensed under the Creative Commons Attribution-NonCommercial-NoDerivatives 4.0 International License. 
attempt at a bridging definition in The Philosophy of Art: "[Architecture] is music in space, as it were a frozen music” (Schelling 2008, 163-164).

The political dimensions of this opposition between the arts, their operating priorities of space vs time, were further illuminated in John Chase and Margaret Crawford's book Everyday Urbanism. Their analysis both cites Michel de Certeau's evocations of the practices of everyday life and, indirectly, the critique of Michel Foucault:

De Certeau drew a distinction between two modes of operation: strategies, based on place, and tactics, based on time. Strategies represent the practices of those in power, postulating "a place that can be delimited as its own and serves as the base from which relations with an exteriority composed of targets or threats can be managed." Strategies establish a "proper" place, either spatial or institutional, such that place triumphs over time. Political, economic, and scientific rationalities are constructed on the strategic model. In contrast, a tactic is a way of operating without a proper place, and so depends on time. As a result, tactics lack the borders necessary for designation as visible totalities: "The place of a tactic belongs to the other." (Chase and Crawford 2008, 9; my emphasis)

Or should that last assertion, for consistency, be reformulated to "The time of a tactic belongs to the other"? Or is placeness + otherness an intrinsic paradox, an intersection awaiting new conceptualizations? Perhaps one perspective that might cut the knot lies in cultural tendencies toward one or the other concepts of time itself, sequential vs synchronous, that might also be translated as a corresponding dialectic between linear work vs cyclical play.

In times deemed unbearable, the urgent call of serious work to be done, especially on behalf of others in need of essential dignity, would seem to avoid any diversion onto the fields of play. Yet this perceived non sequitur might be contested by the notable history of inquiry into the critical agency of play, from Plato through Schiller to Marcuse, or by how certain playing fields, from actual Olympic venues to the fictional courts of David Foster Wallace's Eschaton, shed light on place-making strategies in general, and their resulting inscriptions of territorial dignities/ indignities. Jane V. Curran and Christophe Fricker (2005), in their introduction to an English translation of Schiller's On Grace and Dignity, suggest a premise in the order of the terms in its title. That is, Schiller posits that individual grace (athletic or otherwise) is typically the originator of its sensual, elevating movement in time, a force to be subsequently "corrected" by the collective weight (or gravity) of moral dignity, coalescing into form. But could an alternative sequence perceive dignity as the initial impulse from the collective, the uplift for the prerequisite posture necessary to undergird the subsequent figure of grace that artfully skitters relative to gravity? The first sequence could be seen to derive from the perspective of dominant cultures, while the latter could be seen as more prevalent in the improv- 
isations of minority cultures. Both are surely relevant, and in Schiller's Aesthetic Letters, the union, or perhaps intersection, between grace and dignity is suggested as the province of play, much like the term "place" might be seen as a strong middle (or oscillating) condition between the polarities of space and time.

One example of serious play as a tactical manoeuvre was embodied (literally as dance) in Houston Conwill's art event, The New Cakewalk, enacted at several venues in the 1980s. In addition to its life as performance art, versions under this title were also manifested as floor mappings of cyclical dance notations, collectively attributed to Houston Conwill, his wife Estella Conwill Majozo, and the architect Joseph De Pace. In the catalogue introduction to its 1989 installation as a "cosmogram” at Atlanta's High Museum of Art, curator Susan Krane described the piece as

a metaphorical exploration of the traditional Black slave dance. The work delineates a ritualistic journey through history, as Conwill investigates and illuminates the history of the South, specifically its African-American history. In doing so, he exorcises the horrors and humiliations of slavery and the segregated South (where he was raised) and reasserts mastery over a rich Black cultural legacy - an act of empowerment for the future. (Krane 1989a, 5)

Again, this metaphorical journey from New Orleans to Louisville to Atlanta and to Memphis takes the cyclical form of a traditional southern dance, the Cakewalk, that historically migrated from ritualistic African circle dances to white society ballrooms. This critical irony is embedded in Conwill's ritual re-enactment of slaves' seemingly playful, but empowering stealth tactic of the oppressed mocking their oppressors. The broader cultural history of such "uses-of-play," as Krane further elucidates, is visually mapped by Conwill through "superimposing and transforming three cosmological diagrams: the medieval labyrinth laid in the pavement of the nave of Chartres Cathedral, the diagram of the child's game of hopscotch, and the traditional African-American sign for the crossroads, where blues musicians traditionally gathered with their instruments" (Krane 1989b, 11). In conclusion, Krane refers to Conwill's mappings as a "conceptual architecture" (16) and, for all the improvisation possible in play and dance, the underlying rulebased orders of design (and control) ultimately come into political question.

In that regard, another English phrase, related to play, that I feel bears on (but is rarely invoked in) planning and design is "running-room," which derives from an original formulation by Karl Kraus, as adapted by Hal Foster in his book Design and Crime (2011), and, as further adapted here, implies successive accretions that in themselves enact a mode of creative operation that begs the following larger question regarding design: if the current, lucrative state of design inflation is increasingly harnessed to the strategically constructed, revived city, are there alternate practices of design/non-design that might tactically help sustain a vital running-room intrinsic to the accreting, cycling city? Such a challenge, which implicates various 
significances for "otherness," became the subject of simultaneous investigations in academic design studios at the Georgia Tech College of Architecture and in the first new construction project on Atlanta's historic Auburn Avenue in half a century.

In addressing both the art and politics of US urban development, recent revitalization plans for Atlanta's Auburn Avenue had been described as speaking of, to, and between "other" cultures that have been historically marginalized. During the long period of legal segregation in the US, the resulting compression of the African-American community in certain ways contributed to this street's role as a dynamic hub of economic, cultural, and political vitality. As the home to Dr Martin Luther King, Jr, and the Southern Christian Leadership Conference, Auburn Avenue was thought by many to be the physical cradle of the movement for civil rights and racial justice in the US. However in light of persistent, if not increasing, polarizations afflicting many categories of otherness in current times, some view the movement's incomplete victories in pursuit of the ideals of integration and diversity as having actually regressed, and in the meantime diluted, much of the former creative energy in Atlanta's famous street.

Furthermore, relative to the research question stated above, cities are rarely just either strategically constructed or tactically adaptive; these contrasting urban conceptions often co-exist as jostling communities, and both derive from a fundamental opposition between their operating priorities of space vs time, as previously cited in Chase and Crawford's Everyday Urbanism.

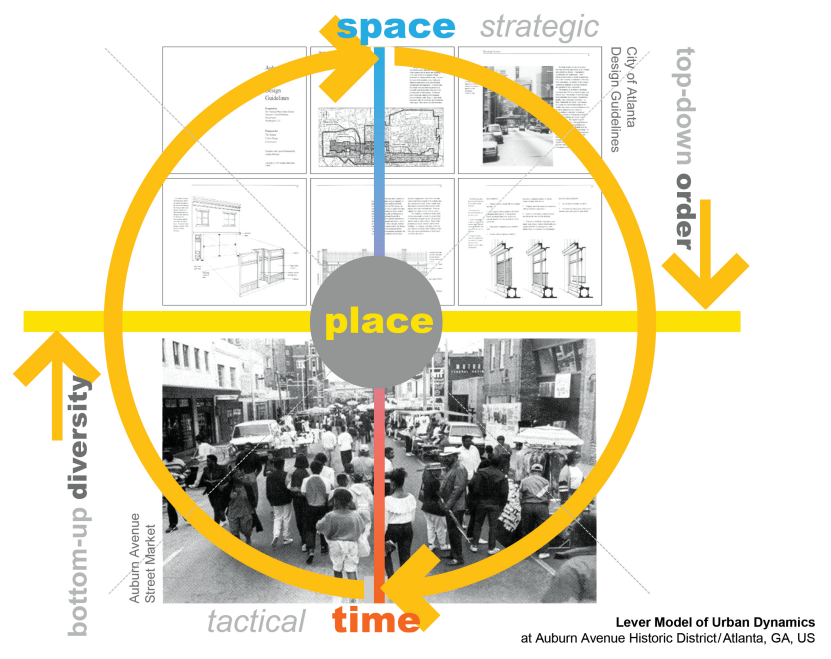

Fig. 1: Lever Model of Urban Dynamics / Auburn Avenue, Atlanta GA US 
So, in further adapting this premise to current situations, the time-tense of the marketable term "revived city" seems to imply a completed, present equilibrium, not always preceded by an actual past decay. Through expanding design controls, a city can attempt to radically collapse the experience of actual time-cycle into a manageable museumification of sufficient historic strata to satisfy the perceived needs of collective identity, while its perpetually "revived" condition mirrors the individual's self-identity with the increasing medical promise of steady-state life. Thus the generally accepted notions of preservation are approximately synonymous at either scale; that is, a "façade-ectomy" might loosely refer to an operation on either a civic or an individual body.

Conversely, the cycling city (referring here to time, not just alternative transportation) implies incomplete successions of erasures and accretions that result from diverse transactions which ideally contribute to sustaining the larger vitality of the community. This ideal may be the alternate objective of public policy and planning: balancing the shared values for order and collective memory which emerge from public consensus with the inevitable private contingencies that maintain the running-room for unforeseen, creative occupations.
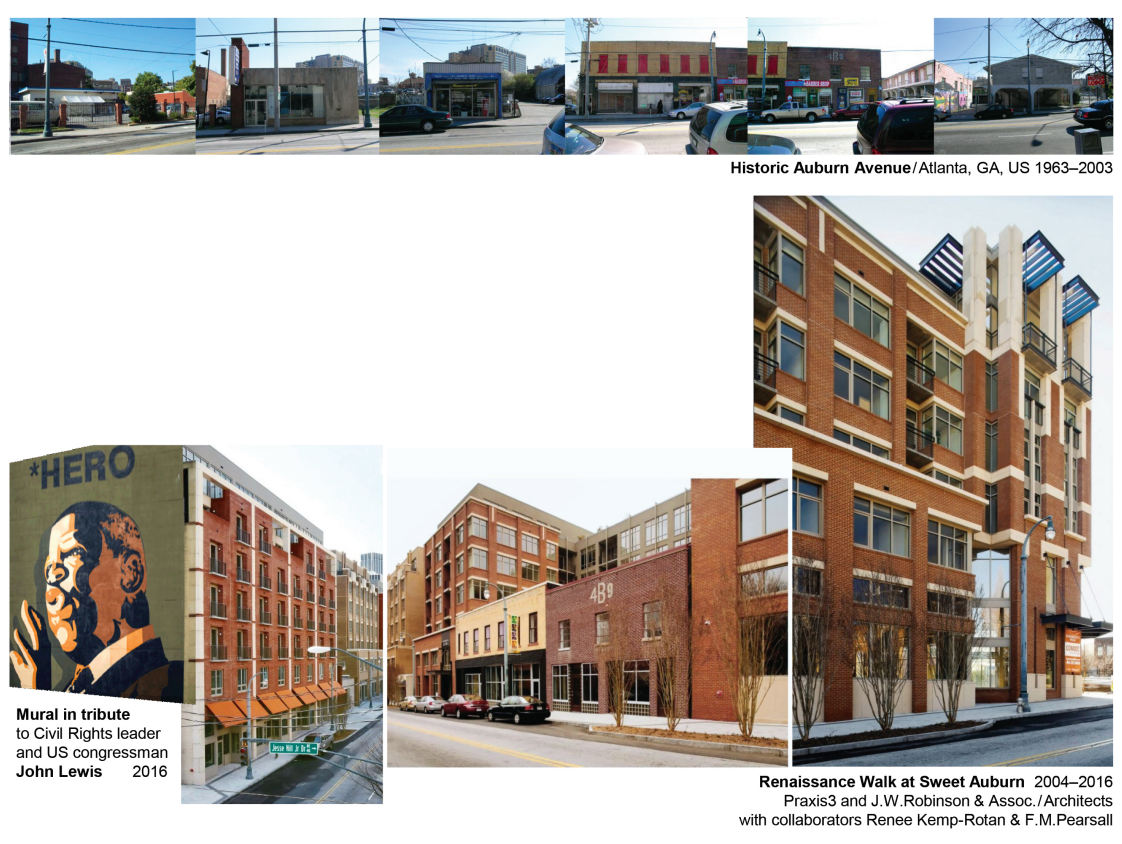

Fig. 2: Renaissance Walk at Sweet Auburn, Atlanta GA US 
This conception of urban vitality suggests a parallel metaphor in agricultural vitality, and contrasts a more supple notion of dynamic sustainability with a more rigid notion of strict preservation. The speculative call by the architect Rem Koolhaas for "Preservation as Crop Rotation" (2004, 464-465) in rapidly growing Bejing draws on a well-known agricultural truism, that is, that the successive cycling of different crops is critical to sustaining ongoing vitality in the soil, whereas the constant maintenance of the same crop without deviation eventually depletes the soil of its nutrients. Obviously, this metaphor is only suggestive in an overall perspective, and not specifically applicable to the essential preservation of important icons of collective memory.

But urban preservation itself, typically prioritizing the iconic and its role in collective memory, is typically a convergence of form(s) toward the abstract rather than a particularization fostering the empathetic. These terms as used here provisionally reference the dialectical opposition outlined in Wilhelm Worringer's Abstraction and Empathy (2014, originally his 1908 doctoral dissertation), and further draw on the writings of Rorty, Levinas, and Žižek. A careful, thorough unpacking of the nuanced relationships among such writers is warranted but beyond the scope of this conversation. I would, however, like to spring from this dialectic toward some tentative mappings/bridgings between the parallel realms of the spatial arts and literary arts suggested at the beginning of this article. At this point, while it probably goes without saying, the crucial pivot-point between their respective roles was first articulated by Victor Hugo with reference to the birth of the modern printing press, "Ceci tuera cela” $(2017,213)$. That is, the book will kill the cathedral, and civilization's most important ideas will be henceforth more clearly communicated, widely disseminated, and permanently recorded via the press than via an architecture of stone.

Words thus take precedence regarding ideas, but as an innate architect (trafficking in diagrams), I will attempt to visually map some conditional relationships between these realms that I hope will be useful for collaborations among us, scoping out our affinities that span between the spatial pole of abstraction (the literary treatise and the architectural plan) and the timeful pole of empathy (the literary journal and the architectural detail). And the loaded term "place" would, at some considerable risk, be posited in between. I say this in homage to Dolores Hayden's thoughtful caveat within her own book, which heralds in its title The Power of Place:

Place is one of the trickiest words in the English language. It carries the resonance of homestead, location, and open space in the city, as well as a position in a social hierarchy [rank]. The authors of books on architecture, photography, cultural geography, poetry, and travel rely on "sense of place" as an aesthetic concept but often settle for "the personality of a location" as a way of defining it. In the nineteenth century and earlier, place also carried a 
sense of the right of a person to own a piece of land, or to be a part of a social world, and in this older sense place contains more political history. Phrases like "knowing one's place" or “a woman's place” still imply both spatial and political meanings. (Hayden 1997, 15-16)

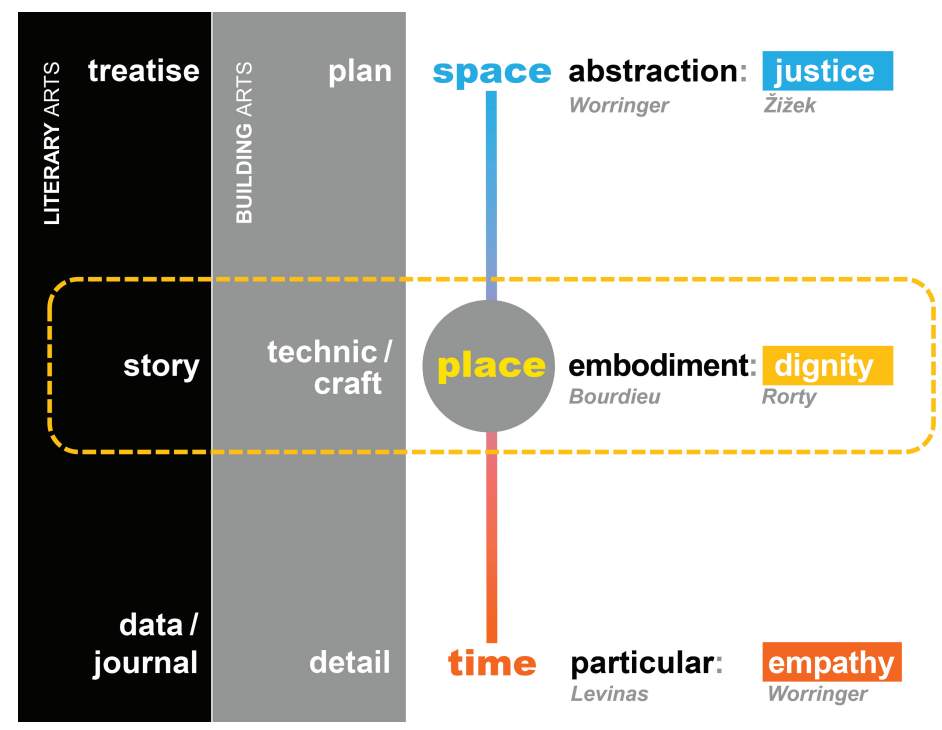

Fig. 3: Socio-Political Mapping across Space and Time

Perhaps, then, other terms along that middle axis could prove more useful for elucidating the goals of dignity than the word "place," offering greater runningroom or play (in this case, meaning both latitude and collaborative participation). For example, between the more individually initiated theoretical treatise and the factual journal, we often find a literary intersection in collective storytelling (often accreted through cycles). Likewise, between the more individually initiated conceptual plan and the material detail, we often find the collaborative embodiment of craft (or collectively acquired knowledge, as in technic).

But just as Hayden suggests that, in English, the positive associations of the word "place" can be eroded by undercurrent connotations of social hierarchy and rank, so too imaginative storytelling lapses can be eroded into suspicions of its yarns, and technic can become merely technique, or worse technocracy. But it is the very risk of such fluid words and their meanings, so intensely charged, in which their recombinative potential lies when diverse disciplines like ours collide. Not in the sense of combat, but in the best sense of "serious play," where the stakes are surely high. For if dignity is intrinsically bound up with reciprocity, variously granted and claimed in exchanges with others, its prospects are usually 
improved not via the strategic linearities of order and control, but via the tactical, cyclical rhythms of gaming and adaptation. And such collective action may be even more crucial at this fragile moment, when the historic oscillations between dignity granted (as in previous judicial acknowledgment of constitutional rights) and dignity claimed (as in fierce legislative negotiation through public engagement and the ballot box) seem rapidly tipping toward the latter - a necessity now of urgent activism.

\section{Works cited}

Chase, John, and Margaret Crawford. Everyday Urbanism. 1999. New York: The Monacelli Press, 2008.

Curran, Jane V., and Christophe Fricker. "Introduction." Schiller's "On Grace and Dignity” in Its Cultural Context. By Friedrich Schiller. Ed. Curran and Fricker. Rochester: Camden House, 2005. 1-18.

Foster, Hal. Design and Crime (and Other Diatribes). 2002. New York: Verso Books, 2011.

Hayden, Dolores. The Power of Place: Urban Landscapes as Public History. Boston: MIT Press, 1997.

Hugo, Victor. Notre-Dame de Paris. 1831. Paris: Éditions Flammarion, 2017.

Koolhaas, Rem. Content. Berlin: Taschen, 2004.

Krane, Susan. "Introduction." Art at the Edge: Houston Conwill. Ed. Krane. Atlanta: High Museum of Art Press, 1989a. 4-6.

Krane, Susan. “The New Cakewalk: A Traveler's Guide.” Art at the Edge: Houston Conwill. Ed. Krane. Atlanta: High Museum of Art Press, 1989b. 9-19.

Schelling, F. W. J. The Philosophy of Art. 1859. Trans. Douglas W. Stott. Minnesota: University of Minnesota Press, 2008.

Worringer, Wilhelm. Abstraction and Empathy: A Contribution to the Psychology of Style. 1953. Trans. Michael Bullock. Eastford: Martino Publishing, 2014.

Stuart Romm, AIA, LEED AP BD + C, is a Professor of the Practice in the College of Design at Georgia Tech, having taught both graduate architectural design studios and courses in ecology and critical practice for twenty-two years. Romm is a founding principal in the Atlanta design firms of Praxis3 and Romm + Pearsall, both multidisciplinary practices focused on civic and educational buildings, advanced automotive facilities, and urban social housing. In these roles, he has developed a special expertise in confronting the emerging intersections between media technologies and public space, as foregrounded in the current Georgia Tech "Library of the Future" renewal project. 